\title{
Determination and evaluation of spatio-temporal trends on the example of PM10 concentration in Poland (2000-2018)
}

\begin{abstract}
Increasing amounts of rapidly growing data are the driving force behind proposing and automating new processing, enabling the extraction of useful information from data. One of such possibilities is determining trends to consider in terms of time and space. Thus far, the analysis of these aspects has been separate and lacked automated tools. Therefore, the authors proposed, implemented, and tested a tool for analyzing spatio-temporal linear trends. The tool was tested on PM10 concentration data in the years 2000-2018. The results, presented as cartographic visualization, were then evaluated, both in terms of time and space. The proposed approach facilitates analyzing spatio-temporal trends and assessing their accuracy; it can be developed using other types of analyzed trends or considering additional factors that influence the trend by using cokriging.
\end{abstract}

Keywords: PM10 concentration, spatio-temporal trends, interpolation

\section{Introduction}

In today's data-filled world, analyzing and synthesizing changes occurring over time is one of the most significant challenges. The possibility of noticing regularities that transpire in time and space enables a better understanding and forecasting of the progression of phenomena. In many cases, however, the analysis of spatio-temporal trends is understood as an analysis of trends in time in a specific space (e.g. Kirk et al., 2012) with spatial aspects used as additional variables (e.g. distances from particular objects) or the assessment of the spatial aspect amounts to a visual qualitative assessment. Although this approach may prove extremely useful for some purposes, it does not consider the spatial variability of temporal trends. The correlations may change in various ways, not only in time but also in space. While the trend goes upward in one area, the phenomenon may be faltering in another. It is impossible to detect this in an approach covering the entire area because it averages such a correlation or may not even show the phenomenon's stability.

The authors of the paper address this problem by proposing and testing the methodology for determining spatio-temporal trends. The authors present the option to model trends in time and space simultaneously and a method for evaluating the model created in such a manner. Subsequently, creating the model, using it for prediction, and evaluating the obtained results are tested on real data using the implemented software.

\section{Time series and trends}

Time series are observations of the same phenomenon measured at different points in time and organized chronologically. Studying time series has been of great interest to econometrics (Kiersztyn, 2013), but it may also prove interesting for other fields. In the analysis 
of time series, the most frequently distinguished elements are (Gąsiorowski, 2015; Malska \& Wachta, 2015) (see fig. 1):

- the constant average level of the phenomenon,

- a trend, i.e., the global direction of changes over time (an increase or a decrease),

- long-term cycles (usually longer than a year),

- periodic and short-term fluctuations (shorter duration),

- interventions (rapid changes resulting from changing external factors),

- a random component (impossible to predict).

As part of the time series analysis, there are attempts to model the components above mathematically (except for the random component, inherently impossible to model). However, as the authors emphasize, even for advanced analysis, the first step in analyzing data should be their visualization on a chart and a general understanding of the analyzed data (Shumway \& Stoffer, 2017a). Despite the discrete nature of the measurements in time, the assumption behind the time series modeling is usually the continuity of time series, and the discrete measurements are treated as sampling from a continuous space of time. Tracking the moving average (Shumway \& Stoffer, 2017a) is the most generic trend analysis (Shumway \& Stoffer, 2017a), while one of the most frequently used methods of time series modeling is determining the trend using a regression model, most often linear (Shumway \& Stoffer, 2017b), and thus described by the following equation:

$$
y=a_{1} x+a_{0}
$$

where:

$y$ - a dependent variable,

$x-$ an independent variable,

$a_{1}-$ the slope of the line (trend parameter),

$a_{0}$ - the intercept.

In this case, the trend parameter $a_{1}$, which determines the slope of the regression line, is usually the most interesting element.

\section{Existing analyses of spatio-temporal trends}

Analyses of temporal trends are primarily specific to the domains of economy, while the analyses of spatio-temporal trends most often appear in the natural or engineering sciences, e.g. hydrology, meteorology, climate science, reservoir engineering, epidemiology, et cetera (Kyriakidis et al., 2004; Kyriakidis \& Journel, 1999; Wang et al., 2021).

The articles dedicated to this issue do not necessarily use the concept of a trend as defined above. Often, the research merely concerns changes in a phenomenon in time and space, considered separately, where the location is only

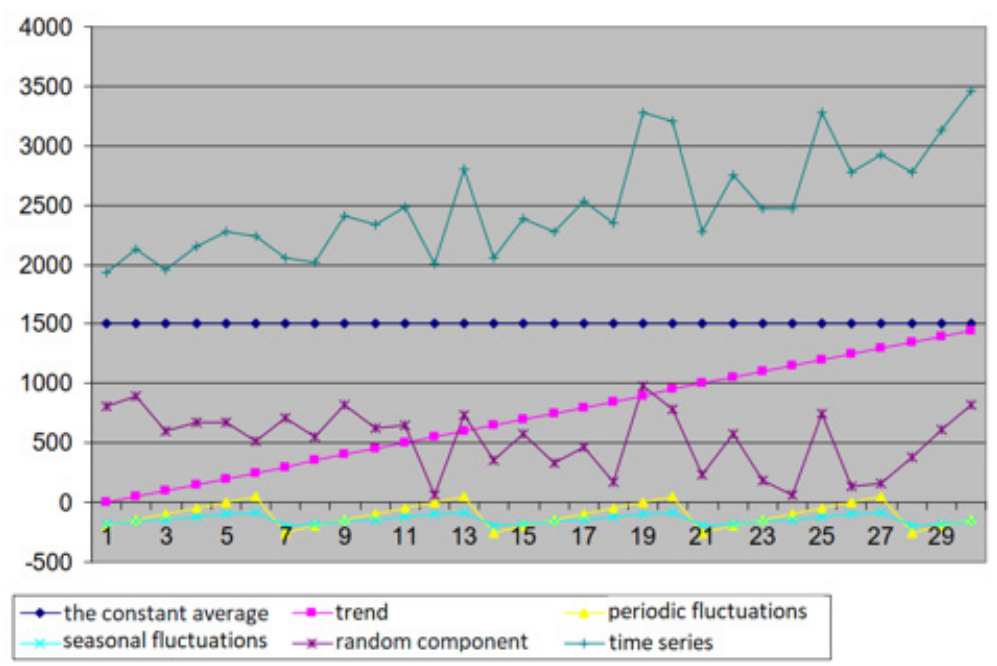

Fig. 1. A time series and its components on the example of fuel sales level (source: Kiersztyn, 2013) 

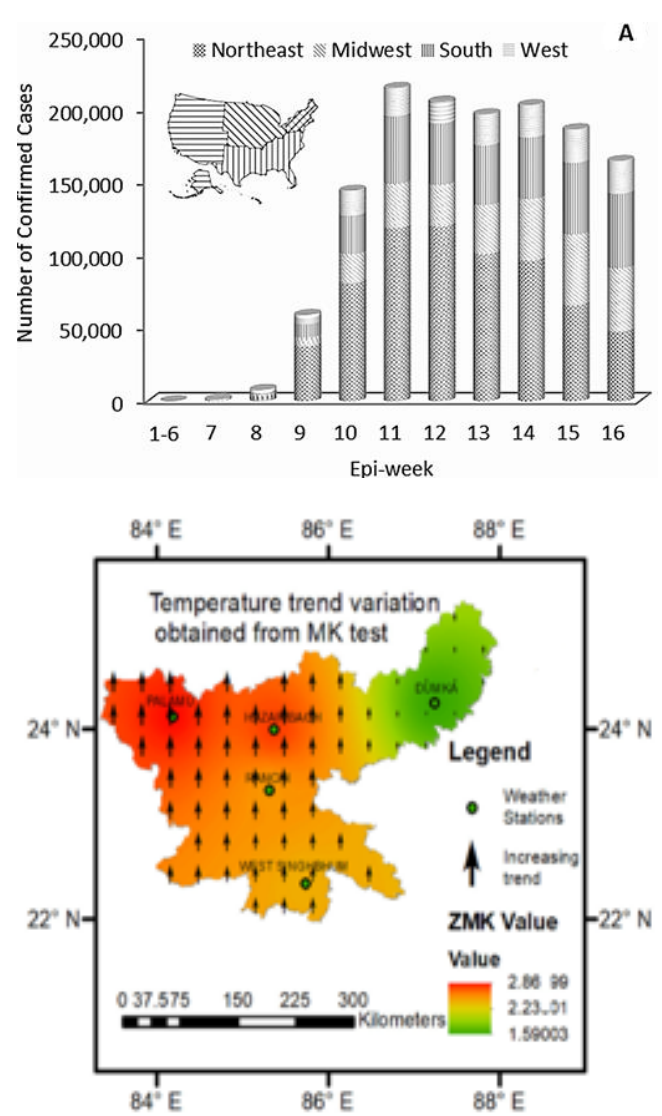

a grouping variable for the trend (e.g. Gupta et al., 2021; Luo et al., 2011; Muhire \& Ahmed, 2015; Talchabhadel et al., 2018; Wang et al., 2021). At best, a map then illustrates the calculated trend values (see fig. 2).

Hydro-climatic data often use two non-parametric tests to study trends: the Mann-Kendall trend test and Sen's slope estimator (e.g. Diop et al., 2016; Hadi \& Tombul, 2018). The first one enables determining whether there is a significant trend in the data and whether its nature is positive or negative. The second one determines the trend's strength, measured by the slope of the line (corresponding to the trend parameter in the linear regression).

Kyriakidis and Journel (1999) conducted a fairly comprehensive but now slightly dated review of the methods for spatio-temporal modeling. The authors drew attention to the fact that scientific disciplines may use different

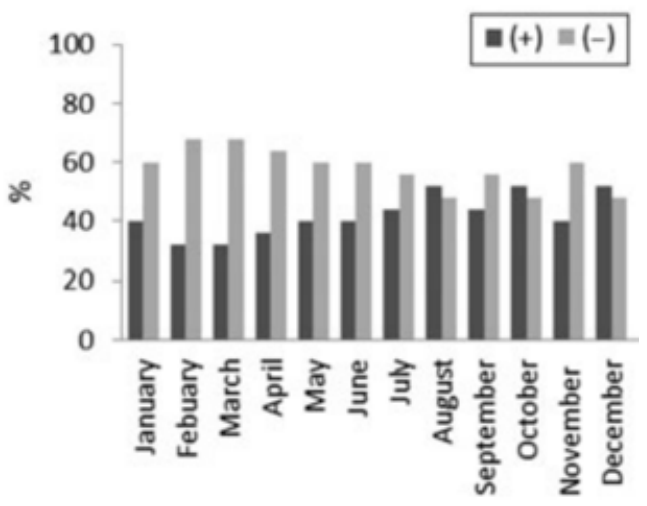

Fig. 2. Trends in time and space considered separately: (A) location as a grouping factor (Wang et al., 2021) (B) time as a grouping factor (on the x-axis percentage of locations: stations with a positive/negative trend in a given month) (Muhire \& Ahmed, 2015) (C) presentation of the calculated trend on a map (Gupta et al., 2021)

approaches and space-time models; they may overlap, thus creating confusion. The authors distinguished two groups of approaches found in the literature, "one calling for a single spatiotemporal random function model, and the other calling for vectors of space random functions or vectors of time series" and pointed to the connections between them.

Bai et al. (2019) published the closest, in terms of the subject, research on trends concerning suspended particulate matter content changes. The article analyzed the amounts of PM2.5 particulate matter and their changes in China. The data, predominantly satellite-derived, was verified with averaged data from air-quality measuring ground-based stations. However, in this model (Bai et al., 2019), a change in the direction (or at least the slope) of the regression line over time is assumed in advance, and the moving average smoothes the measure- 
ment data beforehand. The model does not use the spatial interpolation of data to obtain information for places where no measurements have been made because the data used cover the surface (grid) continuously.

\section{The role of interpolation}

Spatial interpolation enables determining the estimated value of the phenomenon in a place where it has not been directly measured. Based on Tobler's first law of geography (1970) that "everything is related to everything else, but near things are more related than distant things" it enables estimating the values of environmental (and other) phenomena, which are usually spatially continuous, in contrast to their measurements. However, in most cases, it is geographically impossible to measure the entire space. Additionally, other factors such as costs or the availability of a given area (Li \& Heap, 2008) restrict the density of measuring points.

There have been several interpolation methods (Lam, 1983), and their selection influences (sometimes significantly) the obtained results. In (Li \& Heap, 2014), the authors analyzed various interpolation methods, distinguishing them in terms of accuracy, and as global and local, deterministic and stochastic, gradual and abrupt, linear kriging and nonlinear kriging, univariate and multivariate, irregular and regular system. Among the 42 interpolation methods analyzed (Li \& Heap, 2008) there were, e.g. non-geostatistical interpolators such as the nearest neighbor algorithm, Triangular Irregular Network (TIN) method, and the Inverse Distance Weighting method used in this article.

On the other hand, geostatistical methods include various kriging and cokriging, which consider the spatial autocorrelation of the regionalized variable ( $\mathrm{Li} \&$ Heap, 2008). The most straightforward among these methods is the simple kriging method used in this article.

The values describing the phenomenon are most often interpolated; this also applies to the data describing air quality (Lin et al., 2002). However, this study interpolates the values of trends, which only indirectly enable determining the studied phenomenon's value locally at a selected point in space and time. In this approach, it is the temporal model that is subject to continuity (thus gaining a coherent spatial aspect), not individual values describing the studied phenomenon. The result, therefore, is a statistical surface describing the temporal trend of the data.

\section{Research concept and data sources}

Gąsiorowski (2015) outlined the methodology used in this article. The concept bases on the determination of local temporal trends (linear or other) and subsequent spatial interpolation of the parameters of the determined model. It facilitates obtaining a continuous statistical surface that describes the individual parameters of the trend and, thus, obtaining a trend model for any point in the interpolated space. Furthermore, this approach enables observing spatial differences in the phenomenon's trends and predicting the future values of the phenomenon in any place (also in places where measurement data are not collected). Gąsiorowski (2015) also discussed the methodology for calculating model errors while considering the possible spatial differentiation of the model's accuracy.

Jackowska (2020) implemented and tested this approach in her Master's thesis entitled "The concept of ways to analyze spatially differentiated time trends, together with a methodology for assessing the quality of predictions" and defended at the Faculty of Geodesy and Cartography of the Warsaw University of Technology. The implementation took the form of a Python script and included constructing a linear spatio-temporal trend model and its evaluation. The methodology was tested on real data on the measurement of air pollutants (PM10 concentration) made available by the Chief Inspectorate of Environmental Protection in Poland.

The test data were chosen as the air pollution is an important issue which is influencing people health all around the world. The PM10 are the microscopic particles in air which has diameter smaller than $10 \mu \mathrm{m}$, are inhalable and therefor can influence health in both short- and long-term effects (World Health Organization, 2013). The problem is pressing in developing as well as developed countries (Mukherjee \& Agrawal, 2017) being responsible for a serious percent of mortality in some regions. Only PM10 caused $3,79 \%$ of mortality in Bukan city according to Kamarehie et al. (2017) and the mortality by the same particles increased in Mumbay and Delhi from 19,291 and 19,716 cases in 1995 to 
32,014 and 48,651 in 2015 respectively (Maji et al., 2017). In Poland air pollution is constantly monitored by Chief Inspectorate of Environmental Protection (GIOŚ) which not only publishes data but also reports with summary of the monitoring (e.g. Główny Inspektorat Ochrony Środowiska, 2011).

\section{Methodology and its implementation}

The proposed methodology for modeling spatio-temporal trends rests on the assumption that temporal trends, no matter how spatially differentiated, also have a certain correlation in space. Per Tobler's law, the closer they are to each other, the more similar they are. Consequently, the parameters of these trends are correlated spatially; thus, one may treat them as a regionalized variable. Therefore, it is possible to divide the process of determining spatio-temporal trends into the following stages:

- local determination of trend parameters in locations corresponding to the measuring points,

- spatial interpolation of the trend parameters that enables determining a trend model anywhere in a continuous space.

A continuous model determined in such a way facilitates the analysis of the phenomenon in time and space; one may use it both for a retrospective analysis of the nature and spatio- -temporal distribution of the phenomenon and for predicting the further course of the phenomenon trend in time and space.

In this paper, the authors focus on the analysis of the linear trend expressed by the formula (the significance of individual variables as discussed in one of the previous chapters):

$$
y=a_{1} x+a_{0}
$$

The authors used inverse distance weighting and kriging to interpolate the trend parameters to compare the impact of the trend parameter interpolation method on the model's accuracy.

The evaluation of the results is an important element of the model created in such a way, which in this research meant determining the mean absolute percentage error (MAPE):

$$
\overline{M A P E}=\frac{\sum_{j=1}^{M}\left(\frac{1}{N} \sum_{i=1}^{N} \frac{\left|z_{i}^{*}-z_{i}\right|}{z_{i}} * 100 \%\right)}{M}
$$

where:

$z_{i}^{*}$ - the forecast (theoretical) value of the studied phenomenon for a specific point,

$z_{i}$ - the measured (actual) value of the studied phenomenon at the i-th point,

$M$ - the number of measuring points,

$N$ - the number of points in time at which the measurement was done.

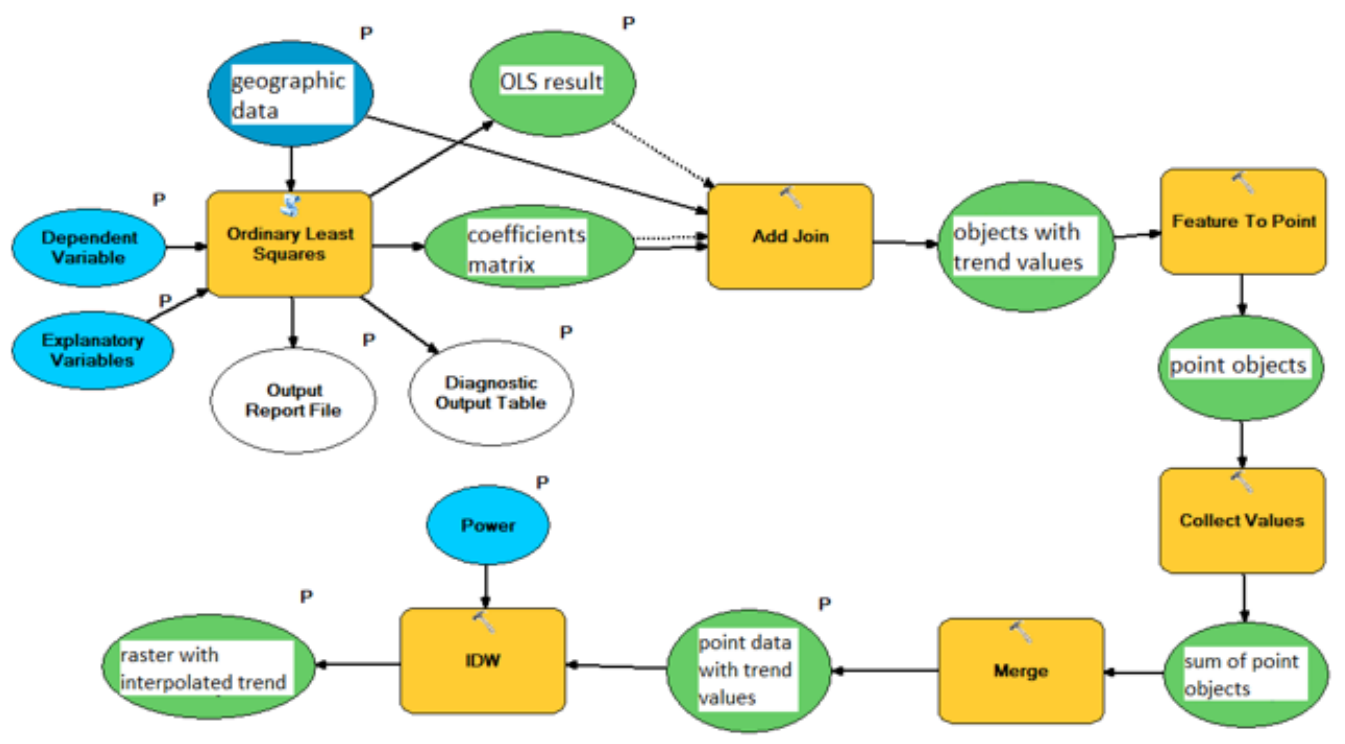

Fig. 3. The flowchart of the trend analysis tool made in ModelBuilder (source: Jackowska, 2020) 
However significant, $\overline{M A P E}$ collectively describes the entire model, but it rests on the mean relative errors for individual measuring points, which one may calculate using the formula:

$$
M A P E=\frac{1}{N} \sum_{i=1}^{N} z_{i}^{*}-z_{i} \vee \frac{*}{z_{i}} * 100 \%
$$

It is possible to analyze their spatial distribution thanks to the determination of local model errors.

The implementation of the model described above used Python, but what is more important is that it was possible to build model fragments in the form of a block diagram in the Model Builder tool in the ArcGIS program (fig. 3) (Jackowska, 2020). Then, necessary elements such as loops or defining appropriate variables were added to this tool in Python.

\section{Test data}

The tests were performed on a data set containing the measurements of PM10 concentration in Poland in the years 2000-2018. The results of these measurements are made available by the Chief Inspectorate of Environmental Protection (Główny Inspektorat Ochrony Środowiska, n.d.). Ms. Aleksandra Kołacz pre-processed the data as part of her Engineer's thesis entitled "Map and cartographic animation of selected air pollution in Poland" (defended at the Faculty of Geodesy and Cartography of the Warsaw University of Technology in February 2021; Kołacz, 2021). These transformations included the standardization of the measuring stations' codes and averaging the measurements to individual years. Consequently, the measuring stations with less than four measurements were removed from the set as it would preclude the tool from calculating the value of the trend parameters. There were two separate subsets distinguished from the data set (see fig. 4):

- a learning subset containing 263 points,

- a test subset containing 18 points distributed evenly throughout the country.

\section{Results}

First, the linear trend parameter was calculated for all measurement points. It amounted to -0.1478 , suggesting a decreasing amount of pollutants in the years 2000-2018. However, the coefficient of determination R2 equal to 0.0037 , along with the scattergram analysis,

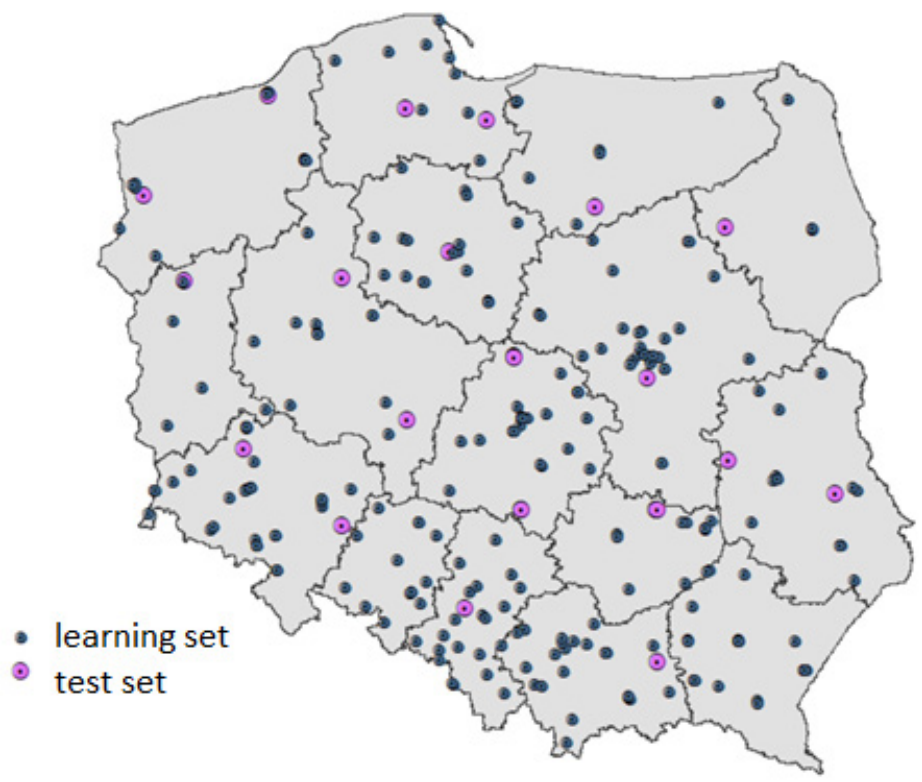

Fig. 4. Distribution of measuring points in Poland and division into a learning set (smaller, gray symbols) and a test set (larger, purple symbols) 


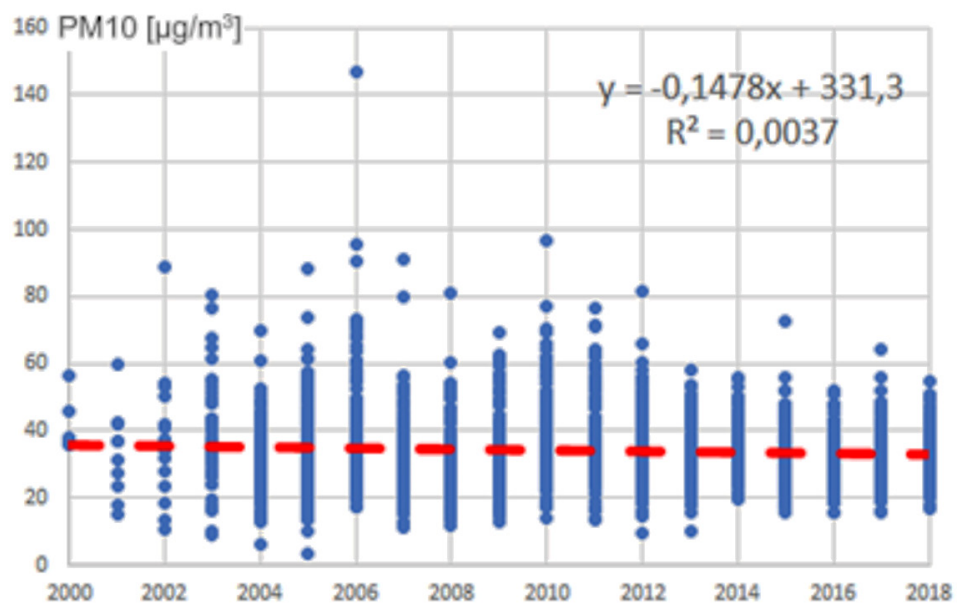

Fig. 5. Averaged annual results for entire Poland: no significant linear trend. Blue points: averaged PM10 measurements $(\mu \mathrm{g} / \mathrm{m} 3)$ for particular points and years. Red dotted line: a regression line

(source: author's original work)

suggested that this trend is insignificant (see fig. 5). One may, therefore, conclude that the phenomenon does not show a linear trend. It is true, but only when considering the scale of the entire country. Locally calculated trends ranged from -10.48 (for the point in Ostrowiec Świętokrzyski) to 4.15 (for one of the points in Kraków) and often (though not for all points) had much better convergence of data and R2 (fig. 6). Sometimes, however, there were not enough measurements to consider the determined trends reliable (as in the measuring point in Ostrowiec Świętokrzyski, fig. 6A). Nevertheless, this does not change the fact that local trends may differ in strength and quality from the generalized idea. Thus, it is possible to observe changes in the trend not only in time but also in space.

Bearing in mind that local trends may be more apparent than the global trend, it was necessary to calculate the parameters of the trend for all points of the learning set, and then interpolate it using two methods, taking into account, respectively, 10 (for the inverse distance weight-
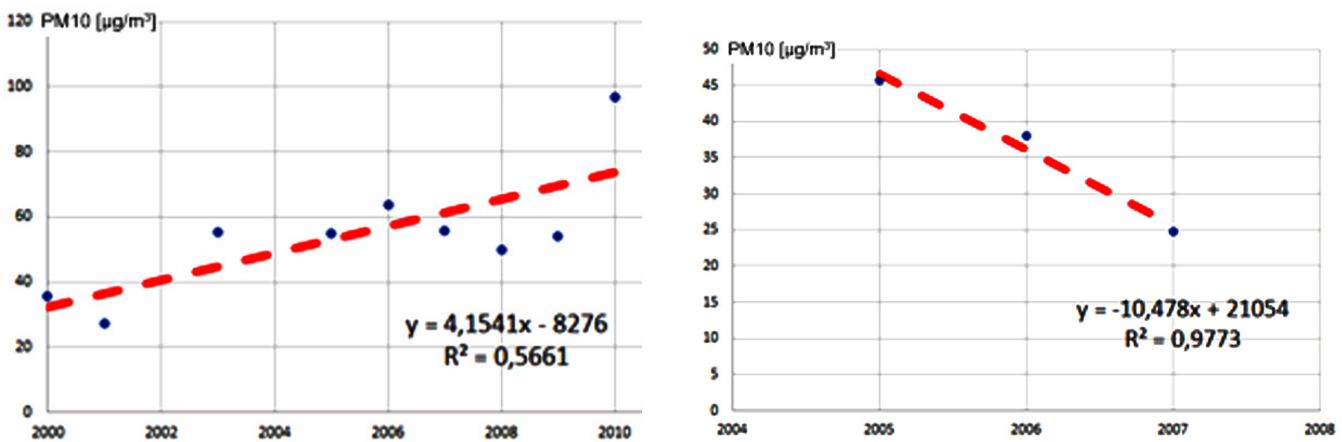

Fig. 6. Selected measuring points with opposite directions of the linear trend: (A) Ostrowiec Świętokrzyski (station: SkOstrowWios) - negative trend with high R2 coefficient, but based only on three measurements and therefore not very reliable (B) Kraków (station: MpKrakowWIOSPrad6115) - a growing trend. Symbols as in figure 5 (source: author's original work) 

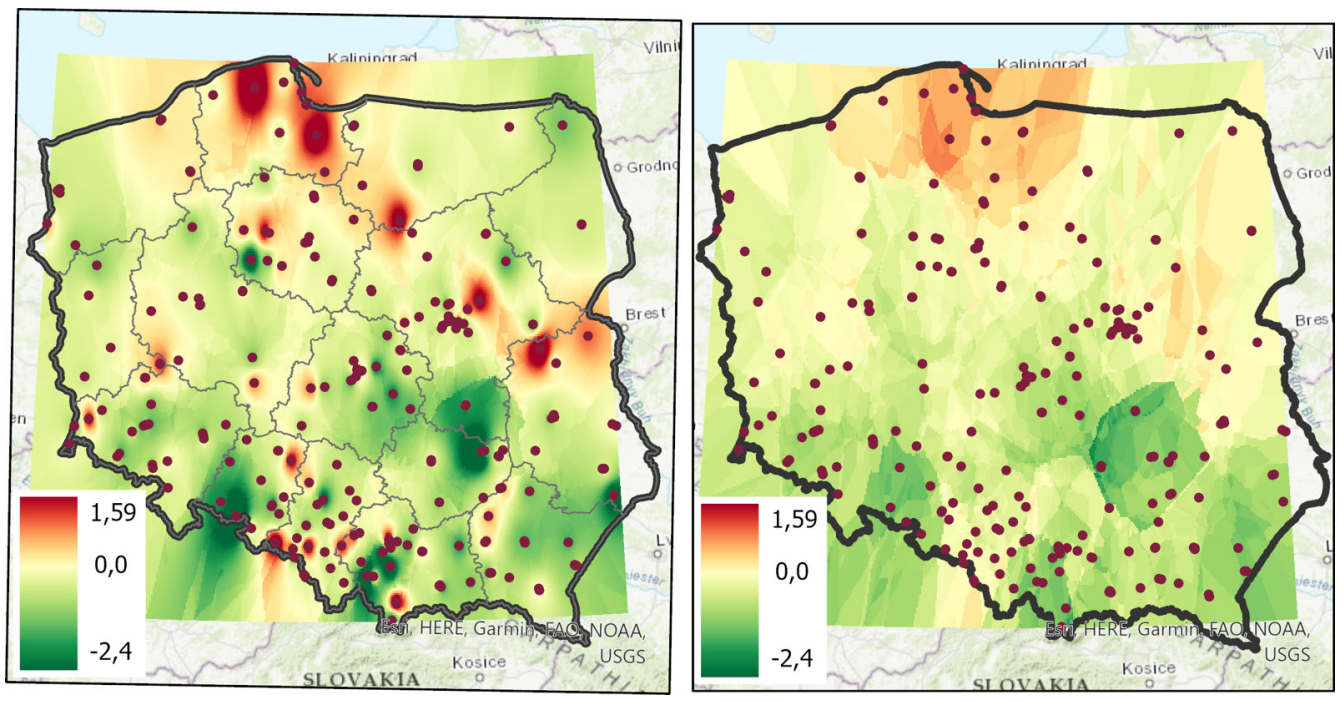

Fig. 7. The trend surface for the change in the value of PM10 concentration in the years (2000-2018), obtained using the method of $(A)$ inverse distances $(B)$ kriging with learning points' locations

ing) and 12 (for simple kriging) of the nearest points (fig. 7).

Regardless of the interpolation method used, one may observe a general tendency: the trend of PM10 particulate matter is downward in Si- lesia and the north of the country, and it is upward in the rest of the country. Trend values range from -9.85 to 4.13 for the inverse distance weighting and from -1.92 to 0.91 for kriging, which tends to flatten the statistical surface.

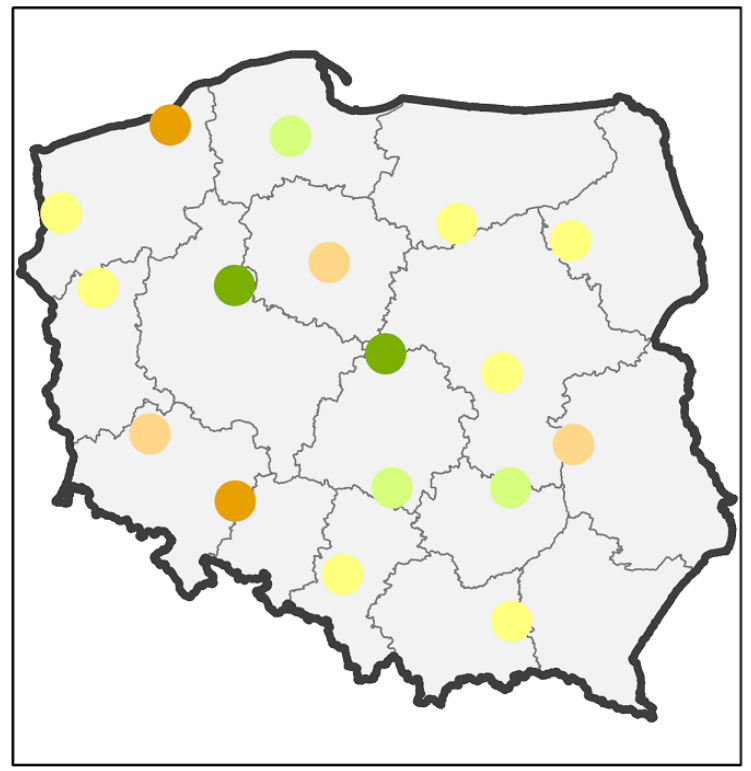

MAPE

$2,0-4,0$

$4,1-6,0$

$6,1-8,0$

$8,1-10,0$

$10,1-12,0$

Fig. 8. Spatial differentiation of MAPE values at the test points (source: author's original work) 
With the trend parameters for all points of the studied area calculated, the MAPE was calculated for the test points (not involved in creating the model). At the measuring point, the mean error value describes the model's time component's quality (as previously shown). At the test points, the MAPE was not higher than $12 \%$ (fig. 8), and the mean MAPE for the entire model was $6.7 \%$.

A small spatial autocorrelation should characterize an error in a well-constructed model. Figure 8 shows the lack of a pattern in the spatial distribution of the MAPE. The linear trend works equally well in all parts of the country.

The differences between the actual trend's parameters at the test points and the parameters of the trend determined for these points as part of interpolation were examined separately (tab. 1, fig. 9). While there has been a general correlation between the downward trend parameter in the south and the upward in the north, a detailed analysis of the results has shown some discrepancies between the interpolated model and the trend parameter's actual values. It particularly applies to the test points for which the trend parameter was strongly positive (over 1); simultaneously, the trend parameters in the nearby stations were much lower. The station located in Puławy (LbPulaSkowo), province Lublin, is a particularly visible example.

Such discrepancies reveal the limitations of Tobler's law and simple interpolation methods that do not consider the influence of additional factors on the parameter value. In this case, they most likely relate to the local source of particulates pollutants. Detection and interpretation of the values deviating from the assumed model may also be interesting because it enables detecting such anomalies and locating their source. It is possible to use more sophisticated interpolation methods such as cokriging when we know the additional factors influencing the model and their location.

\section{Summary and conclusions}

In the current great availability of data sets containing this type of data, determining spatio-temporal trends is paramount. The analyzed example shows that even in the absence of a global trend, it is possible to analyze locally the changes occurring in time. Determining the trends helps understand the nature of the phenomenon, its variability in time and space, and predict the future values, which may have real-life scientific, planning, or business applications. However, determining spatio-temporal trends requires access to measurement data sufficiently complete with regard to both dimensions (time and space). The implementation of the methodology for determining trends prepared by the authors facilitates their automatic processing.

Currently, a large part of the research analyzing the "spatiotemporal trends" actually involves either separate local temporal trend analysis or spatial visualization of the results for a specific point in time (a time-stamp). The number of such analyses found in the literature, and their wide range of topics, demonstrate a need to create models that take both aspects into account. For example, an analysis of epidemiological trends seems to be a particularly interesting and up-to-date potential application. However, despite the topicality and importance of this issue (the COVID-19 pandemic) research in this area does not seem to realize the full potential of spatio-temporal data and analyzes these aspects separately (Wang et al., 2021).

The linear trend used in this study is the simplest; it is often a good first approximation of the direction of changes. It is also easiest to analyze a single trend parameter. Nonetheless, one should remember that the adopted interpolation method may affect the final result even in this case. As part of the demonstrated methodology, it is also possible to use other, more complex trends and interpolate their parameters in space. An exciting issue that will be the subject of future research is determining trends spatially differentiated not only in terms of parameters but also the type of a trend. In this case, however, a simple spatial interpolation of the trend parameters would not be sufficient. Another possibility is to change the trend (its strength/direction but potentially also its nature) over time. Bai et al. (2019) presented such an approach (albeit to a limited extent), and it may become the subject of further research.

Authors are aware that this methodology is insufficient for a serious environmental study of air pollution. This subject would require taking into account a lot more information like emission sources, winds, terrain relief and others (Gao et al., 2020; Główny Inspektorat Ochrony 

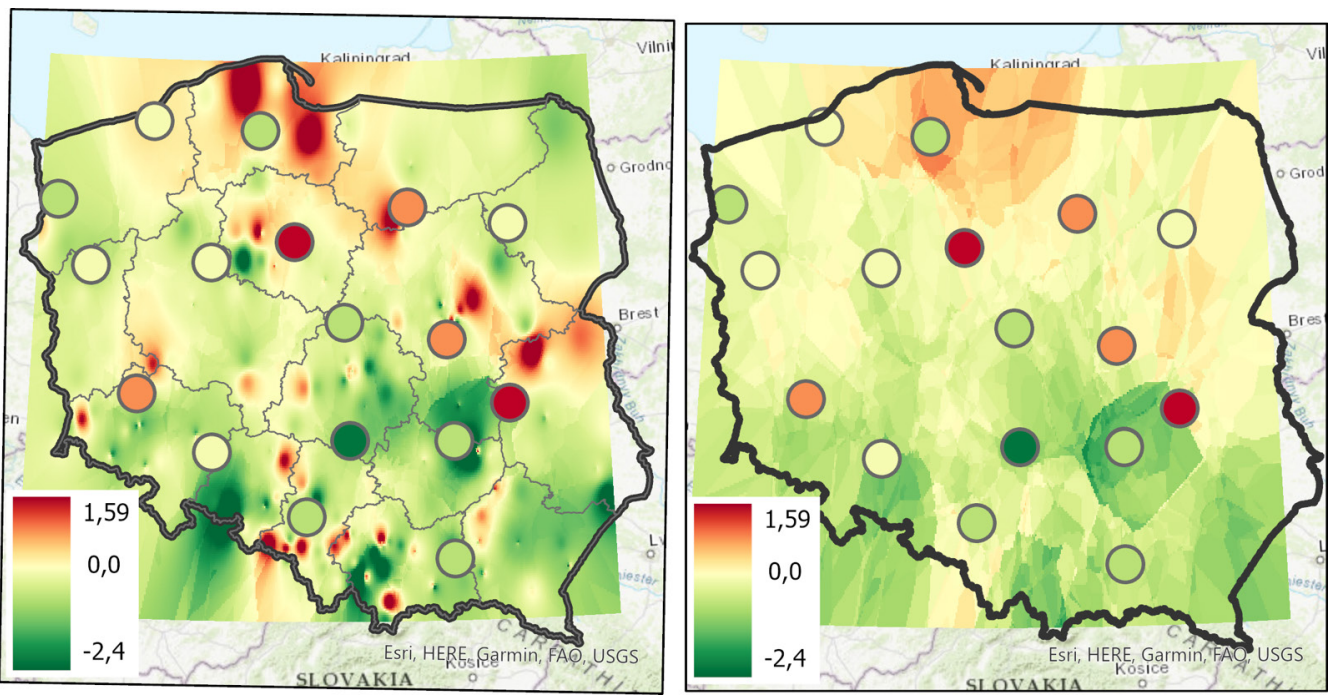

Fig. 9. Correct values of the trend at test points superimposed on the trend surface interpolated using (A) the inverse distance weighting (B) of kriging (source: author's original work)

Tab. 1. Comparison of the modeled and actual trend values for PM10 dust concentration (source: Jackowska 2020)

\begin{tabular}{|l|c|c|c|c|c|}
\hline Measurment station & Real trend & $\begin{array}{c}\text { Modeled trend } \\
\text { (kriging) }\end{array}$ & $\begin{array}{c}\text { Modeled trend } \\
\text { (IDW) }\end{array}$ & $\begin{array}{c}\text { Difference } \\
\text { (kriging) }\end{array}$ & $\begin{array}{c}\text { Difference } \\
\text { (IDW) }\end{array}$ \\
\hline DsPolKasztan & 0,28 & $-0,44$ & $-0,33$ & 0,71 & 0,61 \\
\hline DsOlawZolnAK & $-0,30$ & $-1,19$ & $-1,05$ & 0,89 & 0,74 \\
\hline LdKutnKosciu & $-0,89$ & $-0,31$ & $-0,08$ & $-0,59$ & $-0,81$ \\
\hline LbPulaSkowie & 1,02 & $-0,66$ & $-0,60$ & 1,68 & 1,61 \\
\hline KpTorunLotnisko & 1,07 & 0,04 & 0,27 & 1,02 & 0,79 \\
\hline LuGorzPilsud & $-0,06$ & $-0,34$ & $-1,11$ & 0,28 & 1,05 \\
\hline LdRadomsRoln & $-1,63$ & $-0,48$ & $-0,84$ & $-1,16$ & $-0,80$ \\
\hline MpTuchChopin & $-1,00$ & $-0,42$ & $-1,16$ & $-0,57$ & 0,16 \\
\hline SkStaraZlota & $-1,00$ & $-1,35$ & $-2,42$ & 0,36 & 1,42 \\
\hline PmKosTargo12 & $-0,82$ & 0,81 & 0,25 & $-1,63$ & $-1,07$ \\
\hline PdLomSikorsk & $-0,10$ & $-0,11$ & $-0,57$ & 0,01 & 0,47 \\
\hline MzPiaseczDworWSSE & 0,42 & $-0,33$ & $-0,34$ & 0,75 & 0,76 \\
\hline SkStaracZlota & $-0,69$ & $-1,35$ & $-2,42$ & 0,66 & 1,72 \\
\hline SIZabSkloCur & $-0,99$ & $-0,40$ & $-0,70$ & $-0,59$ & $-0,30$ \\
\hline WmNiTraugutt & 0,29 & $-0,10$ & 0,31 & 0,39 & $-0,02$ \\
\hline ZpSzczAndr01 & $-0,62$ & $-0,30$ & $-0,49$ & $-0,32$ & $-0,13$ \\
\hline WpWagrowLipo & $-0,09$ & $-0,36$ & $-0,61$ & 0,27 & 0,52 \\
\hline ZpKoszalinWSSE & $-0,23$ & 0,19 & 0,01 & $-0,42$ & $-0,24$ \\
\hline
\end{tabular}


Środowiska, 2011; Ścibor et al., 2020). The focus of this article was rather to present methodology then to solve the problem of PM10 concentration modelling in a complete way. Authors believe that the spatio-temporal trend modeling can be useful for modelling air pollution as well as other spatio-temporal phenomena but they need to be analyzed with the full respect of domain knowledge which would add a lot to the modeling. For instance, it is worth noting that other phenomena that change over time and the constant geographical elements also may (and usually do) influence the trend. In such a situation, the modeling of the phenomenon should take into account these additional elements. Another idea to include them indirectly is the use of cokriging at the stage of data interpolation. Cokriging makes it possible to determine the value of a regionalized

\section{Literature}

Bai, K., Ma, M., Chang, N.-B., \& Gao, W. (2019). Spatiotemporal trend analysis for fine particulate matter concentrations in China using high-resolution satellite-derived and ground-measured PM2.5 data. Journal of Environmental Management, 233, 530-542. https://doi.org/10.1016/j.jenvman.2018. 12.071

Diop, L., Bodian, A., \& Diallo, D. (2016). Spatiotemporal trend analysis of the mean annual rainfall in Senegal. European Scientific Journal, 12(12), 231. https://doi.org/10.19044/esj.2016.v12n12p231

Gao, S., Wang, Y., Shan, M., Teng, Y., Hong, N., Sun, Y., Mao, J., Ma, Z., Xiao, J., Azzi, M., Chen, L., \& Zhang, H. (2020). Wind-tunnel and modelled PM10 emissions and dust concentrations from agriculture soils in Tianjin, Northern China. Aeolian Research, 42, 100562. https://doi.org/10.1016/j. aeolia.2019.100562

Gąsiorowski, J. (2015). Szeregi czasowo-przestrzenne - analiza trendu. In A. Fiedukowicz, J. Gąsiorowski, \& R. Olszewski (Eds.), Wybrane metody eksploracyjnej analizy danych przestrzennych (spatial data mining) (pp. 97-104). Wydział Geodezji i Kartografii Politechniki Warszawskiej.

Główny Inspektorat Ochrony Środowiska. (n.d.). Ocena jakości powietrza - bieżące dane pomiarowe. Retrieved March 2019, from http://powietrze.gios.gov.pl

Główny Inspektorat Ochrony Środowiska. (2011). Analiza stanu zanieczyszczenia powietrza pyłem PM10 i PM2, 5 z uwzględnieniem składu chemicznego pyłu oraz wpływu źródeł naturalnych. Zabrze.

Gupta, N., Banerjee, A., \& Gupta, S. K. (2021). Spatio-temporal trend analysis of climatic variables over variable while considering an additional phenomenon changeable in space.

In the modeling of spatio-temporal trends, it is crucial to have the option to evaluate the obtained results. Known types of errors prove effective, e.g. the MAPE that assesses the time aspect or assessing the difference between the actual and modeled trend parameter at test points. However, apart from the standard evaluation of the MAPE value at test points, one should pay attention to the spatial distribution of the error values and the possible spatial autocorrelations. In this context, one should not forget the role of visualizing results: properly selected visualization methods both help evaluate the obtained results and understand the spatial distribution of the obtained errors. Moreover, this may help detect model errors and data anomalies, which may be of analytical interest.

Jharkhand, India. Earth Systems and Environment, 5(1), 71-86. https://doi.org/10.1007/s41748-02100204-X

Hadi, S. J., \& Tombul, M. (2018). Long-term spatiotemporal trend analysis of precipitation and temperature over Turkey. Meteorological Applications, 25(3), 445-455. https://doi.org/10.1002/met.1712

Jackowska, M. (2020). Koncepcja sposobów analizy trendów szeregów czasowych zróżnicowanych przestrzennie, wraz z oceną jakości dokonywanych predykcji [Master's thesis]. Warsaw University of Technology.

Kamarehie, B., Ghaderpoori, M., Jafari, A., Karami, M., Mohammadi, A., Azarshab, K., Ghaderpoury, A., \& Noorizadeh, N. (2017). Estimation of health effects (morbidity and mortality) attributed to PM10 and PM2.5 exposure using an air quality model in Bukan city, from 2015-2016 exposure using air quality model. Environmental Health Engineering and Management, 4(3), 137-142. https://doi.org/10.15171/ EHEM.2017.19

Kiersztyn, A. (2013). Analiza szeregów czasowych. https://pracownik.kul.pl/files/12167/public/analiza_ szeregow_czasowych/AnalizaSzeregowCzasowych Konwersatorium.pdf

Kirk, R. W., Bolstad, P. V., \& Manson, S. M. (2012). Spatio-temporal trend analysis of long-term development patterns (1900-2030) in a Southern Appalachian County. Landscape and Urban Planning, 104(1), 47-58. https://doi.org/10.1016/j.landurbplan. 2011.09.008

Kołacz, A. M. (2021). Mapa i animacja kartograficzna wybranych zanieczyszczeń powietrza na terenie 
Polski [Engineer's thesis]. Warsaw University of Technology.

Kyriakidis, P. C., \& Journel, A. G. (1999). Geostatistical space-time models: a review. Mathematical Geology, 31(6), 651-684. https://doi.org/10.1023/ A:1007528426688

Kyriakidis, P. C., Miller, N. L., \& Kim, J. (2004). A spatial time series framework for simulating daily precipitation at regional scales. Journal of Hydrology, 297(1-4), 236-255. https://doi.org/10.1016/j.jhydrol. 2004.04.022

Lam, N. S.-N. (1983). Spatial interpolation methods: a review. The American Cartographer, 10(2), 129-150. https://doi.org/10.1559/152304083783914958

Li, J., \& Heap, A. D. (2008). Spatial Interpolation Methods: A Review for Environmental Scientists. Geoscience Australia, Record 2008/23. http://www. ga.gov.au/webtemp/image_cache/GA12526.pdf

Li, J., \& Heap, A. D. (2014). Spatial interpolation methods applied in the environmental sciences: a review. Environmental Modelling \& Software, 53, 173-189. https://doi.org/10.1016/j.envsoft.2013. 12.008

Lin, Z., Mo, X., Li, H. [Hong-xuan], \& Li, H. [Hai-bin] (2002). Comparison of three spatial interpolation methods for climate variables in China. Acta Geographica Sinica, 57(1), 47-56.

Luo, P., He, B., Takara, K., Razafindrabe, B. H. N., Nover, D., \& Yamashiki, Y. (2011). Spatiotemporal trend analysis of recent river water quality conditions in Japan. Journal of Environmental Monitoring, 13(10), 2819-2829. https://doi.org/10.1039/ c1em10339c

Maji, K. J., Dikshit, A. K., \& Deshpande, A. (2017). Disability-adjusted life years and economic cost assessment of the health effects related to PM2.5 and PM10 pollution in Mumbai and Delhi, in India from 1991 to 2015. Environmental Science and Pollution Research International, 24(5), 4709-4730. https://doi.org/10.1007/s11356-016-8164-1

Malska, W., \& Wachta, H. (2015). Wykorzystanie modelu ARIMA do analizy szeregu czasowego. Zeszyty Naukowe Politechniki Rzeszowskiej. Elektrotechnika, 34 [292](3), 23-30.
Muhire, I., \& Ahmed, F. (2015). Spatio-temporal trend analysis of precipitation data over Rwanda. South African Geographical Journal, 97(1), 50-68. https:// doi.org/10.1080/03736245.2014.924869

Mukherjee, A., \& Agrawal, M. (2017). World air particulate matter: Sources, distribution and health effects. Environmental Chemistry Letters, 15(2), 283-309. https://doi.org/10.1007/s10311-017-0611-9

Shumway, R. H., \& Stoffer, D. S. (2017a). Characteristics of time series. In R. H. Shumway \& D. S. Stoffer (Eds.), Springer Texts in Statistics. Time Series Analysis and Its Applications (pp. 1-44). Springer International Publishing.

Shumway, R. H., \& Stoffer, D. S. (2017b). Time series regression and exploratory data analysis. In R. H. Shumway \& D. S. Stoffer (Eds.), Springer Texts in Statistics. Time Series Analysis and Its Applications (pp. 45-74). Springer International Publishing.

Ścibor, M., Bokwa, A., \& Balcerzak, B. (2020). Impact of wind speed and apartment ventilation on indoor concentrations of PM10 and PM2.5 in Kraków, Poland. Air Quality, Atmosphere \& Health, 13(5), 553-562. https://doi.org/10.1007/s11869-020-00816-8

Talchabhadel, R., Karki, R., Thapa, B. R., Maharjan, M., \& Parajuli, B. (2018). Spatio-temporal variability of extreme precipitation in Nepal. International Journal of Climatology, 38(11), 4296-4313. https://doi. org/10.1002/joc.5669

Tobler, W. R. (1970). A computer movie simulating urban growth in the Detroit region. Economic Geography, 46, 234. https://doi.org/10.2307/143141

Wang, Y., Liu, Y., Struthers, J., \& Lian, M. (2021). Spatiotemporal characteristics of the covid-19 epidemic in the United States. Clinical Infectious Diseases, 72(4), 643-651. https://doi.org/10.1093/ cid/ciaa934

World Health Organization (2013). Review of evidence on health aspects of air pollution: REVIHAAP project: technical report (No. WHO/EURO: 20132663-42419-58845). World Health Organization. Regional Office for Europe. 